\title{
An Electro-Mechanical Pro-Tray Seeder for Sowing Vegetable Seeds
}

\author{
Divaker Chelladurai
}

\begin{abstract}
Developing technology to pick and place singulated vegetable seeds into pro-trays is a felt need amidst the nursery growing entrepreneurs. A simple electro-mechanical machine was developed which does not require sophisticated controls and a separate source of vacuum. The unit can fill in the growth media in the pro-trays, level it off, compact the media in the cells, pick and place singulated vegetable seeds in the compacted cells and finally re-top the pro-tray for watering and germination. The whole process is done on a flat belt conveyor moving in steps of inter-cellular distance of the pro-tray, thus doing the sequence of operations in each row of the pro-tray. The machine on being tested provided about 60 per cent of singulation in flat seeds, but 100 per cent in round seeds. Flat seeds, if pelleted, provided 100 per cent singulation. The machine has a through-put of 80 trays per hour of operation.
\end{abstract}

Keywords-picker needle, pro-tray, vacuum, vegetable seeds.

\section{INTRODUCTION}

\section{I} the world during the past three decades, due to new technology in vegetable production. Vegetable production having grown above 100 million tones, India has achieved self sufficiency in producing vegetables and has also started exporting them due to the open seed policy of the Government of India. Many corporate firms have now entered the arena of vegetable seed production.

In this scenario of booming vegetable production, pro-tray grown seedlings are preferred by vegetable growers for manual transplantation than the conventionally grown nursery. Reasons are that the complexity of producing virile nursery in their own farms is completely avoided, Excessive labour cost and underlying risks of nursery mortality are eliminated. Number of entrepreneurs have now entered into the business of raising and supplying pro-tray grown seedlings to vegetable farmers. Moreover, the tray seedlings grown under protected environments have remarkable vitality and crop stand after being transplanted. This is because all the vital growth inputs to the seedling are provided strategically and precisely so that they acquire these attributes ultimately. The mortality due to manual handling of seedlings during transplantation and transplanting shock are considerably reduced.

In these circumstances, appropriate automation of the production process of pro-tray grown seedling is to be

Revised Manuscript Received on December 05, 2019.

* Correspondence Author

Divaker Chelladurai*, School of Agricultural and Processing Sciences, Kalasalingam Academy of Research and Education, Krishnankoil, Tamil Nadu, India. Email:divaker@gmail.com addressed soon. The most tedious and time consuming process in pro-tray grown seedling production is to sow single seeds into the pro-tray cells, presently being done manually.

Most of the vegetable crops such as tomato, chilli and cabbage are now hybrids and their seeds are very expensive and to be used judiciously. The conventional practice of raising pro-tray nursery is to place the seeds manually into the media filled cells of the pro-trays. The seedling after germination, becomes root bound with the soil and become suitable for being transplanted into the plot for production. Efforts have been made internationally to develop automated pro-tray seeders. Sophisticated high speed seeders are available now in western countries, which are prohibitively expensive to import and use in Indian farm scenario.

Gaikwad and Sirohi [1] designed a pneumatic pro-tray seeder and tested its performance for sowing tomato and capsicum. The seeder makes indents in each row of the plug tray cells and places single seeds in the cells simultaneously. The suction pressures were 4.91 and $3.92 \mathrm{kPa}$ at nozzle diameters of 0.46 and $0.49 \mathrm{~mm}$ to deliver $90 \%$ seed singulation in capsicum and tomato respectively. The capacity ranged between 38,000 and 60,000 cells $\mathrm{h}^{-1}$ and the cost of sowing 1000 cells was only 15.27 per cent of the estimated cost of manual sowing. Garba and Shupilov [2] developed a device for sowing vegetable seeds in cell trays. Experiments were conducted to optimize the working parameters of the seeder namely the vacuum pressure in the seeding drum and the suction hole diameter for ensuring effective seed singulation. Tomato and ball pepper seeds were sown into 64 celled plug trays and the optimal vacuum pressure was found to be between 2.1 and $2.2 \mathrm{kPa}$ and suction hole diameter $1.0 \mathrm{~mm}$ to achieve more than 90 per cent seed singulation. Davood et. al [3] constructed a robot for planting tomato in plug trays. Observations on a prototype showed that it can plant seeds in at a nominal capacity of 17000 cells per hour at a positional accuracy of 88 per cent. A continuous feeding precision vacuum tray seeder was developed by EL-Gobapshy et.al. [4] for sowing single seeds in the plug tray cells. It was evaluated on two tray types of 84 and 209 cell trays under four suction pressures and four seed plate hole sizes on cucumber and cabbage seeds. Singulation efficiency was 90 per cent at suction pressure of $1.5 \mathrm{kPa}$ and hole diameter of $1.6 \mathrm{~mm}$ for cucumber; and was 75 per cent at $0.90 \mathrm{kPa}$ and $0.8 \mathrm{~mm}$ for cabbage respectively. The tray seeder's productivity was about 200 trays $^{-1}$ with a 5 to 12 per cent reduction in seeding cost .

This paper explains the

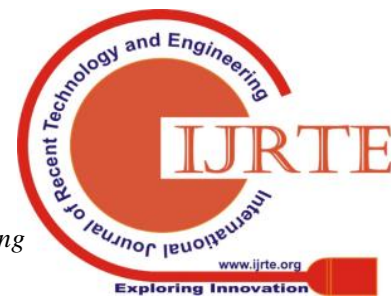




\section{An Electro-Mechanical Pro-Tray Seeder for Sowing Vegetable Seeds}

development of an automated pro-tray seeder which is wholly compressed air/ vacuum.

electro-mechanical and does not need a separate source of

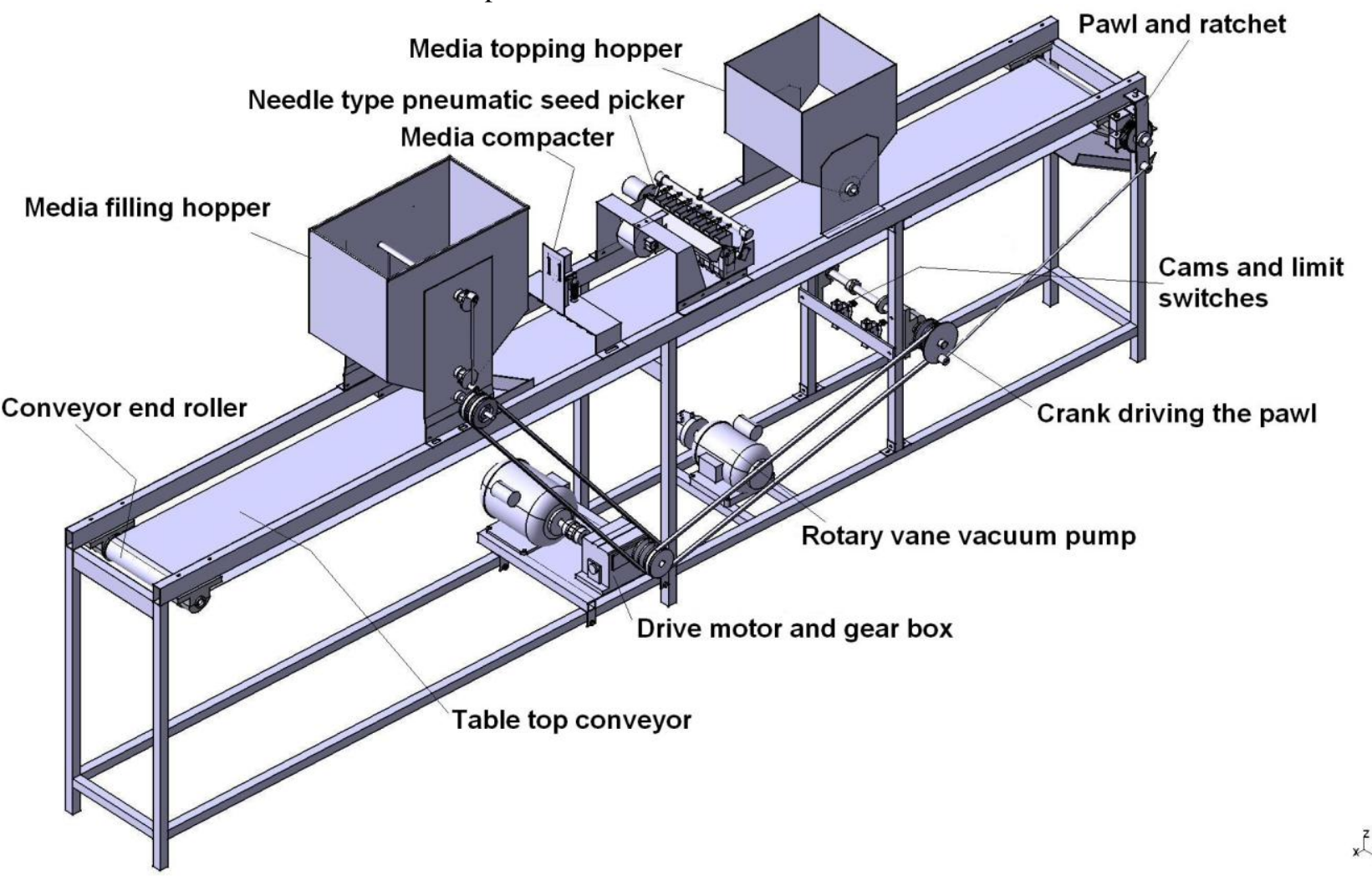

Fig. 1. Automated pro-tray seeder

\section{CONSTRUCTION AND WORKING}

The machine illustrated in Fig. 1 has a belt conveyor moving the fed pro-trays from the left side of the conveyor in steps of the inter-cellular distance. A pawl and ratchet mechanism is provided to move the flat conveyor belt at steps to cater the inter cellular distance of a standard 98 celled pro-tray. The conveyor's drive roller was designed to match the chosen ratchet of a standard 98 celled pro-tray. The conveyor's drive roller for the required intercellular distance is as below:

Required linear movement of the belt

$=36.7 \mathrm{~mm}$

$=$ inter cellular (centre to centre $)$ distance between plugs of a standard $14 \times 7$ pro-tray.

Fractional revolution of roller / step $=\pi \mathrm{D} / 36.7$ where " $\mathrm{D}$ is the Pitch Circle diameter of the conveyor's drive roller in $\mathrm{mm}$

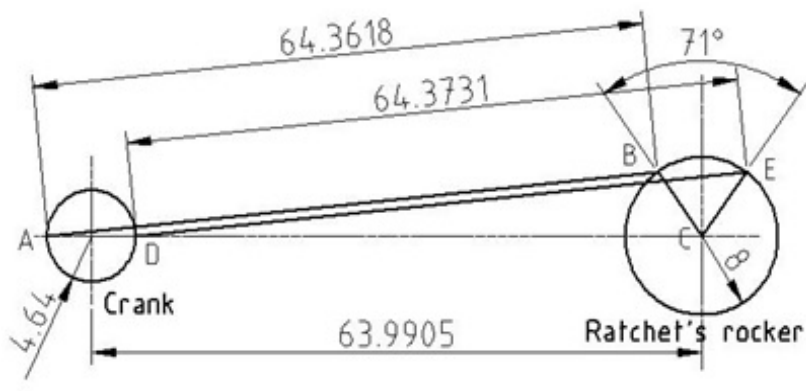

Fig. 2. Pawl and ratchet drive design

Since we have chosen 66 teeth on the ratchet driving the roller, the number of teeth to be moved per step

$$
=66 /(\pi \mathrm{D} / 36.7) \approx 13 .
$$

Then $\mathrm{D}=(66 \times 36.7) / 13 \pi=59.3 \mathrm{~mm}$

Actual roller diameter $=59.3-2.0=57.3 \mathrm{~mm}$

(accounting for belt thickness)

The ratchet drive to the conveyor drive roller was designed next as below:

Let ' $x$ ' be crank radius, ' $R$ ' be ratchet's rocker arm, ' $C$ ' be the centre distance between crank centre and ratchet centre and ' $\mathrm{L}$ ' be the connecting rod length. And we have chosen $\mathrm{R}$ $=80 \mathrm{~mm}$ and $\mathrm{C}=640 \mathrm{~mm}$.

Angle of ratchet movement per step of conveyor's linear movement corresponds to 13 teeth moved out of the 66 teeth on the pawl $=(13 \times 360 / 66)=71 \mathrm{deg}$

From Fig. 2 (dimensions in $\mathrm{cm}$ ),

In triangle $\mathrm{DEC}$,

$\mathrm{L}^{2}=\mathrm{R}^{2}+(\mathrm{C}-\mathrm{x})^{2}-2 \mathrm{R}(\mathrm{C}-\mathrm{x}) \cos 125.5$

$$
\begin{aligned}
& =82+(64-x)^{2}-2(8)(64-x) \cos 125.5 \text { (cosine law) } \\
& =82+642+x^{2}-128 x+594.6368-9.2912 x
\end{aligned}
$$

In triangle $\mathrm{ABC}$ of Fig.2,

$$
\begin{aligned}
\mathrm{L}^{2} & =\mathrm{R}^{2}+(\mathrm{C}+\mathrm{x})^{2}-2 \mathrm{R}(\mathrm{C}+\mathrm{x}) \cos 54.5 \\
& =82+(64+\mathrm{x})^{2}-2
\end{aligned}
$$

(8) $(64+x) \cos 54.5$ (cosine law)

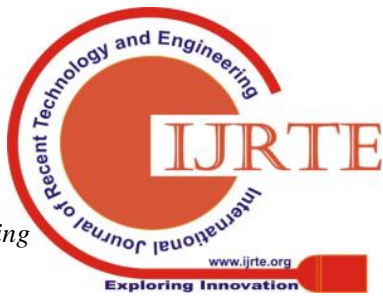




$$
=82+642+x^{2}+128 x-594.6368-9.2912 x
$$

Equating and canceling common terms,

' $\mathrm{x}$ ', crank radius $=4.64 \mathrm{~cm}=46.4 \mathrm{~mm}$.

and ' $\mathrm{L}$ ', the connecting rod length $=643.7 \mathrm{~mm}$.

When the drive motor of the conveyor is switched on, the pawl and ratchet mechanism moves the belt and the pro-trays on it in steps of inter-cellular spacing. The machine can fill the prepared growth media at a metered quantity in each cell row and then level it off to the top of the pro-tray. The metering roller inside this feed bin is a fluted roller which meters the exact quantity of media into each cell row. The excess media, that is shaved off from the pro-tray top, falls on the conveyor and travels out to be collected at the end of conveyor to be recycled back. The media metering tank also has an agitator inside the bin for smooth flow of media down.

Fig. 3 shows a seven cell compactor as mounted next on the machine shown in Fig. 1, which compacts down the media in the cells of each tray row providing a small indent for the seeds to be centered after the drop. The compactor carries seven buttons on a downward moving plunger and actuated by a $230 \mathrm{~V}$ AC solenoid coil. On actuation, the plunger is pushed down by the solenoid to compact the seven cells of the cell row of pro-tray aligned at the bottom.

An automated vacuum needle picker mounted next in Fig. 1, picks up seven singulated seeds from a vibrating seed tray and drops them into the seven cells of the tray row in alignment below. The picker head as shown in Fig. 4 is a PVC pipe which carries 7 hypodermic needle receptors at a spacing corresponding to the centre to centre distance of cells in a typical $14 \times 7=98$ celled pro-tray. Each of these receptors can hold a hypodermic needle of any required size. The needles in turn are blunted at the ends and act as seed picker needles if a suction pressure is available on their tips. The picker head carrying these pickers are vacuum sealed at the ends with dummies. The vacuum is applied to the picker head through a $6 \mathrm{~mm}$ hose adapter. The picker head in turn is carried by a set of rocker arms holding it on either side, which can oscillate about a central pivot placed on an appropriate chassis frame. A $3 \mathrm{~W} 60 \mathrm{rpm}$ geared DC motor with appropriately mounted limit switches are used to stop the drive at the desired angular positions and electrical relays drive the rocker back or forth as required. Vibration is imparted to a pivoted seed feed tray through an eccentric driven by a small 10 watt AC motor. The need for vibratory motion is two folded, one for loosening the seed mass to allow the picker needles to catch the seeds easily and the other for sifting down the dust particles to the sloping bottom of the tray.

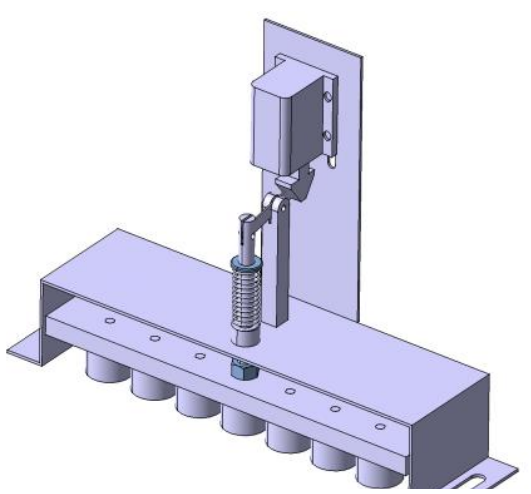

Fig. 3. Tray cell compactor

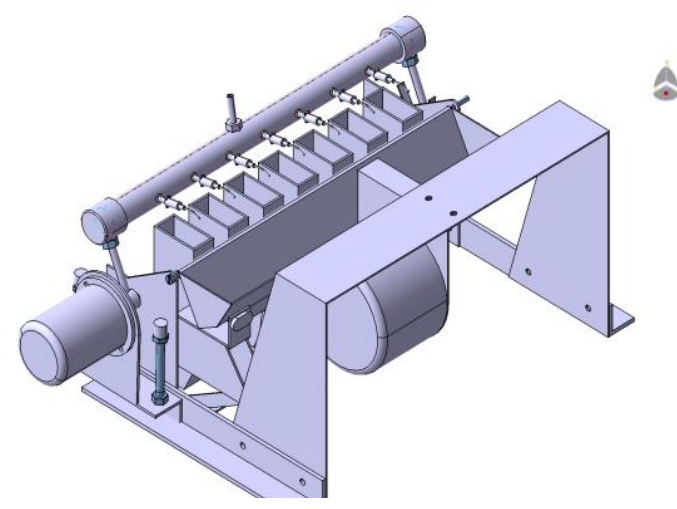

Fig. 4. Automated seed picker

All the picker needles simultaneously plunge into the seed mass kept in the vibrating tray. When the suction pressure is available in the picker head, these picker needles pick the seeds. The magnitude of seed feed tray vibration is adjustable by varying the size of the eccentric depending on the size of the seeds being picked. When the picker head is swung back to the drop position, vacuum is shut down and the seeds that are held by the picker needles drop down. An appropriately arranged array of convergent drop tubes lead off the dropped seeds to the respective cells in the row of the pro-tray

$$
\frac{p_{1}}{\rho}+\frac{v_{1}^{2}}{2}+g z_{1}=\frac{p_{2}}{\rho}+\frac{v_{2}^{2}}{2}+g z_{2}+\frac{\Delta p_{1-2}}{\rho}
$$

positioned below. The needle sizes can also be changed according to the size of seeds picked. Since the seed pick/drop mechanism needs to be stopped when the seed tray is not present below it, an optical sensor is incorporated in the $\frac{2\left(p_{1}-p_{2}\right)}{\rho}=\frac{16 Q^{2}}{\pi^{2}}\left(\frac{1}{D_{2}^{4}}-\frac{1}{D_{1}^{4}}\right) \begin{aligned} & \text { circuit to sense the tray's } \\ & \text { presence. } \\ & \text { A rotary vane mono-block }\end{aligned}$ type of AC driven vacuum pump is provided from which the vacuum is sourced to the picker needle array. Air flow rate for the vacuum pump was computed according to

where $\mathrm{p}=$ pressure; $\rho=$ density; $\mathrm{v}=$ velocity; $\mathrm{g}=$ gravitational constant $\left(9.81 \mathrm{~ms}^{-2}\right)$ and $\mathrm{z}=$ geodetic height

Pressure drop through the orifice because of velocity increase can be calculated as:

$$
V_{1}=\frac{4 Q}{\pi D_{1}^{2}} V_{2}=\frac{4 Q}{\pi D_{2}^{2}} \text { as }
$$

where $\mathrm{Q}=$ volumetric flow rate and inlet, $D_{1}=$ bigger 


\section{An Electro-Mechanical Pro-Tray Seeder for Sowing Vegetable Seeds}

diameter, $\mathrm{D}_{2}=$ smaller diameter and $\mathrm{v}_{1}$ and $\mathrm{v}_{2}$ are respective velocities.

Expressing in terms of flow rate

$$
\begin{aligned}
& Q=\sqrt{\frac{1}{1-\left(\frac{D_{2}}{D_{1}}\right)^{4}}} \frac{m_{2}^{2}}{4} \sqrt{\frac{2\left(p_{1}-p_{2}\right)}{\rho}} \\
& \text { Making } \quad E=\sqrt{\frac{1}{1-\left(\frac{D_{2}}{D_{1}}\right)^{4}}}
\end{aligned}
$$

leads to

$$
Q=\operatorname{cet} \frac{\pi D_{2}^{2}}{4} \sqrt{\frac{2\left(p_{1}-p_{2}\right)}{\rho}}
$$

where $\mathrm{C}=$ coefficient of discharge and $\mathrm{e}=$ expansion coefficient. Coefficient of discharge can be calculated using the following equation (ISO):

$$
\begin{aligned}
& C=0.5961+0.0261 \beta^{2}-0.216 \beta^{\mathrm{a}}+0.000521\left(\frac{10^{6} \beta}{\operatorname{Re}}\right)^{0.7}+ \\
& +\left(0.0188+0.0063\left(\frac{19000 \beta}{\operatorname{Re}_{D}}\right)^{0.8}\right)\left(\frac{10^{6}}{\operatorname{Re}_{D}}\right)^{0.3} \beta^{3.5}+ \\
& +\left(0.043+0.08 e^{-10 L_{1}}-0.123 e^{-7 L_{1}}\right)\left(1-0.11\left(\frac{19000 \beta}{\operatorname{Re}}\right)^{0.8}\right) \frac{\beta^{4}}{1-\beta^{4}}- \\
& -0.031\left(\frac{2 L_{2}}{1-\beta}-0.8\left(\frac{2 L_{2}}{1-\beta}\right)^{1.1}\right) \beta^{1.3}
\end{aligned}
$$

where $\beta=$ diameter ratio $\mathrm{D}_{2} / \mathrm{D}_{1}, \mathrm{ReD}=$ Reynolds number, $\mathrm{L}_{1}$ and $L_{2}$ are coefficients appropriate to the type of pressure tapping

Expansion coefficient e can be calculated (for gases only):

$$
e=1-\left(0.41+0.35 \beta^{4}\right) \frac{\Delta p}{\chi p_{1}}
$$

where kappa $=$ isentropic coefficient $=1.4$ for air

When flowing fluid is gas, then it is considered as incompressible and ideal.

Based on the above calculations, a $0.5 \mathrm{hp}$ single phase AC operated rotary vane type monoblock vacuum pump was selected that can provide a maximum of 95 percent vacuum at a flow rate of $3 \mathrm{~m}^{3} \mathrm{~h}^{-1}$

All the above actions including the appropriate electrical valving for seed pickup, compactor actuation and picker motor movement were realized through an electro-mechanical circuit shown in Fig. 5. Cams were provided strategically on the main drive shaft of the machine, which implements the sequence of actions required. A media re-topping unit shown in Fig. 1 is mounted next which tops up the seeded pro-tray with a fine layer of media thus completing the process. The sequence of the above said operations are completed in each cell row of the trays moving in steps on the conveyor. About 80 sown trays can be prepared in an hour.

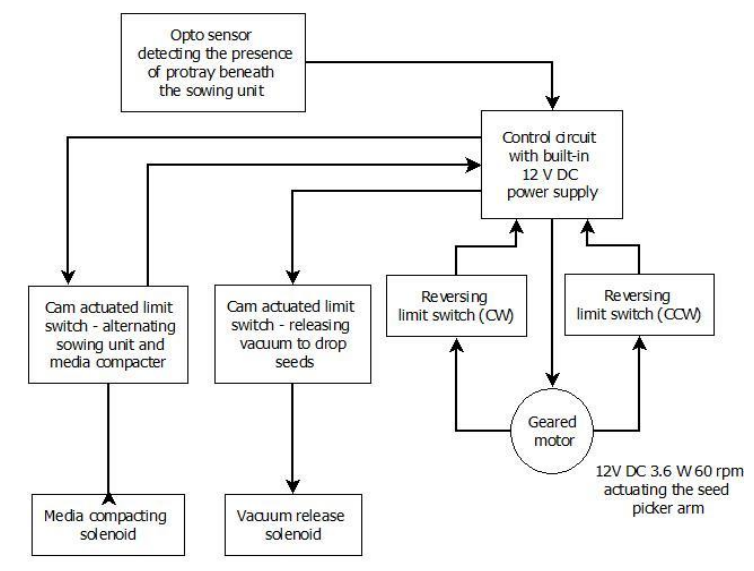

Fig. 5. Control circuit

\section{EVALUATION OF THE SEEDER}

The device was evaluated for its picking performance on different type of seeds. The picking cycle was replicated a minimum of 20 times on each type of seed with selected sizes of picker needles as required. The suction pressure developed with different sized picker needles ( $16 \mathrm{G}$ to $22 \mathrm{G}$ ) ranged from 9 to $12 \mathrm{~mm}$ of $\mathrm{Hg}$, which was found to suffice the requirements of lifting pelleted / raw seeds.

Since the seed picking is effected by vacuum, the needles tend to pick multiples if seeds are flat like that of tomato and chilli. About $40 \%$ of multiples were observed while picking, though the rest were singulated seeds. However if round seeds such as cabbage and cauliflower are picked, the singulation is almost $100 \%$. Most of the vegetable crops such as tomato, chilli and cabbage are now hybrids and their seeds are very expensive. Hence there is a need for using the seeds judiciously and placing of singulated seed in each cell has become mandatory. Hence the only option of singulating flat seeds is to pelletize them into round shapes. The developed seeder has been designed to singulate and place pelleted seeds of $3 \mathrm{~mm}$ sizes also. Technology of seed pelleting is now available and can hence be implemented to get precise singulations.

\section{ACKNOWLEDGMENT}

The support offered by the Agricultural Engineering College and Research Institute, Tamil Nadu Agricultural University, Coimbatore, India is acknowledged with gratitude..

\section{REFERENCES}

1. B. B. Gaikwad and N. P. S. Sirohi. "Design of a low-cost pneumatic seeder for nursery plug trays". Biosystems engineering. 99, pp.322 - 329, 2008.

2. M. B. Garba and A. A. Shupilov. "Results of experimental researches of the process of Single-grain seeding of vegetable crops in cassette drum-vacuum seeding device". UDC631.53.04: 635 Science-journals of Belarus and the CIS member states, 2015.

3. J. Davood, M. Zamani, M. Abasgholipour, B. Mohammadi. and A. A Ranji. "Design, construction and preliminary evaluation of tomato seed rooting for greenhouse seed trays". Journal of Agricultural Machinery (Iran), Vol. 5, No. 2, Fall - Winter 2015, pp. 242-250.

4. H. M. EL-Ghobashy., T. H. A Mohamed, A. M. EL-Ashker and Y. A. Shabaan. "Development of a 
Locally Vacuum Vegetable Seeder for Nursery Trays". J. Soil Sci. and Agric. Eng., Mansoura Univ., Vol. 7(8), pp. 595- 602, 2016.

\section{AUTHORS PROFILE}

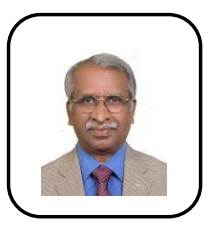

Dr. Divaker Durairaj Chelladurai having a $\mathrm{Ph} . \mathrm{D}$ in Agriicultural Engineering is a former Professor of Farm Machinery and Dean of Agricultural Engineering College and Research Institute, Tamil Nadu Agricultural University, Coimbatore, India. He has a professional experience of 36 years. His research Interests are in the Design of field machinery; Soil tool modeling , Application of Electronics and Computers in Agriculture, Electrostatics for pesticide spraying and Precision Farming Applications. He has implemented number of research projects from DST, UGC and CSRI of India. He had trainings in NIRAE, Tsukuba, Japan and FABE, Ohio State University, USA. He has guided more than 15 students into their $\mathrm{PhD}$ and MTech degrees in $\mathrm{Ag}$ Engineering and has published over 30 research papers in Peer reviewed International scientific journals and two books/ book chapters. He is also a life member of the Indian Society of Agricultural Engineers. He has been an expert member of policy making and research review committees for ICAR at National level. 